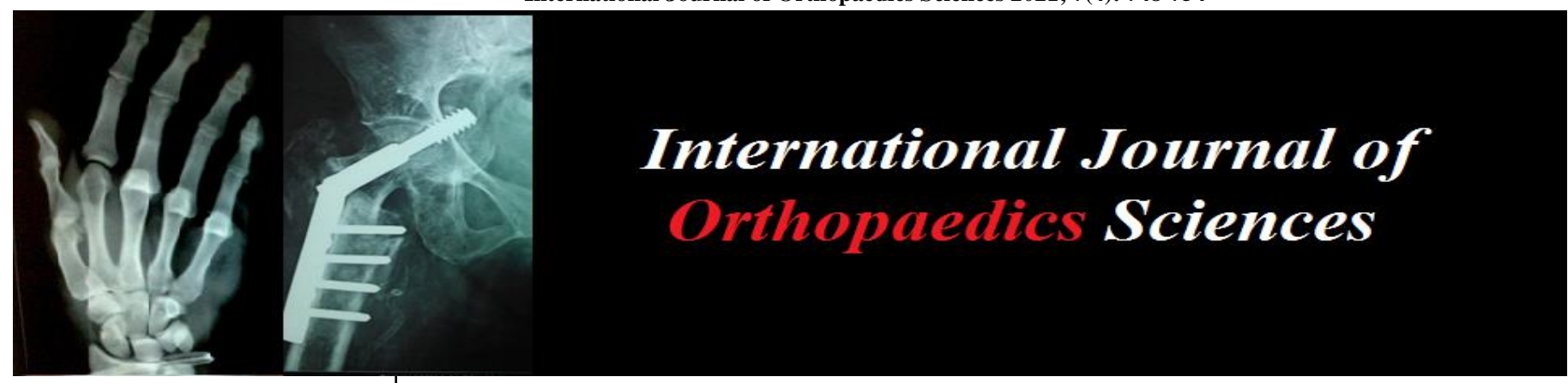

E-ISSN: 2395-1958

P-ISSN: 2706-6630

IJOS 2021; 7(4): 748-754

(C) 2021 IJOS

www.orthopaper.com

Received: 10-06-2021

Accepted: 16-07-2021

\section{RM Chandak}

MBBS, M.S., Department of

Orthopedics, Chandak Nursing

Home, Sitabuldi, Nagpur,

Maharashtra, India

\section{Mohit Sharma}

Senior Resident, Department of Orthopaedics, Dip SICOT,

FIPM. Dr. Baba Saheb

Ambedkar Hospital and Medical

College, Rohini, New Delhi,

India

\section{Alankar Ramteke}

MBBS, M.S., Department of Orthopedics, Chandak Nursing

Home, Sitabuldi, Nagpur,

Maharashtra, India

Jignesh Pandya

MBBS, M.S., Department of

Orthopedics, Chandak Nursing

Home, Sitabuldi, Nagpur,

Maharashtra, India

Kuldeep Deshpande

MBBS, M.S., Department of

Orthopedics, Chandak Nursing

Home, Sitabuldi, Nagpur,

Maharashtra, India

\section{Types of depression in intraarticular tibial condylar fractures and modes of elevation: A retrospective series of 950 cases}

\author{
RM Chandak, Mohit Sharma, Alankar Ramteke, Jignesh Pandya and \\ Kuldeep Deshpande
}

DOI: https://doi.org/10.22271/ortho.2021.v7.i4k.2963

\section{Abstract}

Background: Tibial condylar fractures are often associated with depression of articular surface and commonly used classifications describe various fracture patterns. However, these classifications do not address the types of depression of articular fragments, so we tried to classify various types of depressions of articular surface associated with tibial condylar fractures and developed a treatment algorithm based on our study, with an aim to facilitate step-wise approach for classifying and modes of elevation of depressed fragments.

Material and Methods: This was an intervention study of 950 tibial condylar fractures operated at our center by single surgeon between March 2002-2016. These patients were retrospectively evaluated for radiographic and functional outcomes.

Results: The study revealed mean post op condylar tilt of $5.38^{\circ} \pm 3.55,(0-12)$, condylar widening of 2.68 $\pm 1.25(0-6 \mathrm{~mm})$, articular step $2.98 \pm 1.86(0-8 \mathrm{~mm})$, valgus tilt $6.64^{\circ} \pm 3,(0-13)$ and mean knee society score of $84.39 \pm 6.3,(60-98)$ at follow-up of 12 months post-op. All the cases were followed up for at least 24 months, mean follow-up time $87.39 \pm 35.97$ months $(7.25+2.91$ years $)$.The average radiographic bony union time was $17.07 \pm 1.4$, (14-22wks) weeks, the average full weight bearing time was $15.04 \pm 2$, $(12-24)$ weeks. The average range of motion of the affected knees at 12 months was $127.6^{\circ} \pm 4.46,(120$ 135).

Conclusion: Based on our study of the various types of depression of articular surface in tibial condylar fractures, we were able to classify depression, facilitate steps of surgery and improving outcomes.

Keywords: Tibial condylar depressions, types of depression, modes of elevation, Antero-posterior (AP), Computed tomography (CT)

\section{Introduction}

Tibial condylar fractures are complex injuries produced by high or low-energy trauma. They principally affect young adults or the 'third age' population. Sequential treatment is recommended in complex fracture (Schatzker type 5 and type 6 ) patterns ${ }^{[1]}$.

Tibial condylar fractures are often associated with depression of articular surface due to combination of axial loading and Varus/ Valgus applied forces. Restoration of articular congruity and alignment of the proximal fragments, leads to better restoration of osteoligamentous alignment, which is most important determinant of future knee function. Proper restoration of even complex tibial condylar fractures can have excellent long term function, provided good articular congruity is achieved along with mechanical alignment of the limb with proper soft tissue healing ${ }^{[2,3]}$.

Various classifications have been proposed for proximal tibial fractures like Hohl and Moore, ${ }^{[4]}$ Schatzker ${ }^{[5]}$ and AO/OTA classification, ${ }^{[6]}$ and various newer classifications like 10 column classification by Krause ${ }^{[7]}$ and Luo's three column classification ${ }^{[8]}$. However, the current existing classifications of tibial condylar fractures do not take into consideration types of depression associated with the tibial condylar fractures, nor offer specific surgical strategy for elevation of depressed articular fragment associated with these injuries. Present scientific literatures have advised intra-articular fragments should be elevated and fixed appropriately, but there are no specific standardized guidelines for the elevation and fixation of these depressed articular fragments ${ }^{[9-11]}$.
Corresponding Author: Mohit Sharma

Senior Resident, Department of Orthopaedics, Dip SICOT,

FIPM. Dr. Baba Saheb

Ambedkar Hospital and Medica College, Rohini, New Delhi, India 
Based on their experience in treating these injuries, authors tried to classify various types of depressions of articular surface associated with tibial condylar fractures. Authors also developed a treatment algorithm based on proposed classification to facilitate elevation of depressed fragments ensuring improved post-operative outcomes.

\section{Material and Methods}

The study comprised of a series of 950 depressed tibial condyle fractures operated between March 2002 and March 2016 at our center by a single surgeon. All closed fractures, who presented to us within 3 weeks from the time of injury, within age group 20-75 years, with informed consent were included. We excluded patients aged $<20$ years and $>75 y e a r s$, pathological fractures, bilateral fractures, articular fracture without depression (Schatzker Type1), skeletally immature patients, compound fractures, fractures with neurovascular compromise, associated compartment syndrome and patients lost to follow-up.

All the patients were admitted after clinical and radiological diagnosis and routine laboratory investigations were done. Radiographs were taken for both knees and CT Scans of affected knee were obtained preoperatively. All the patients were splinted in above knee (ankle to mid-thigh) anterior and posterior well-padded fiberglass slabs in $15^{\circ}-20^{\circ}$ flexion after excluding compartment syndrome and neurovascular compromise. In cases with highly unstable injuries with comminution and, bony spike tethering the skin, initial management was done using spanning external fixation along with well-padded back slab. Patients who developed blisters on presentation or who had gross swelling and hematoma were closely monitored for compartment syndrome. Those patients with abrasions or skin wounds were provided with appropriate wound care using longitudinal rolls of 5\% Povidone iodine impregnated Gamgee rolls and appropriate heel padding. All patients were given limb elevation and were encouraged to do active toe movements and ankle movement. Patients were taken for surgery after appropriate soft tissue response, which was judged by absence of erythema, decreased tissue edema, appearance of 'wrinkle sign'.Deep breathing exercises, spirometry and chest physiotherapy was started on admission.

\section{Planning the Elevation}

Radiographs (AP, Lateral view), CT Scan were done in all cases preoperatively, fractures were first classified according to Schatzker classification and then the associated depression was classified according to the classification for depression proposed by senior author (RMC). Based on the fracture pattern, configuration of implants to be used was decided. (Fig.1)

Traction views in antero-posterior and lateral view and $15^{\circ}$ caudal view on image intensifier was obtained before starting the surgery to study the depth of depression and to determine the site of cortical window ${ }^{[9]}$. Two radiolucent cuboidal knee blocks ( 9 inches x 6 inches $\times 4$ inches) were used to help in imaging and condylar tilt control.

Depressed articular fragment elevation was planned on the basis of the classification type, depth and direction of tilt of the depressed fragment. The site of insertion of bone tamp in the metaphysis is either through medial and lateral window, or through the fracture site (window of opportunity), or through a sub-meniscal approach. This is affected either directly under vision or image assisted. (Fig 2)

\section{Surgical Procedure}

All the patients underwent surgery under spinal or general anesthesia as per decision of anesthesia team. High thigh pneumatic tourniquet was used in all cases. The surgical approaches were determined by various factors such as type of fracture classification, type of depression, determining window for elevation. Patient positioning in supine, prone or lateral for surgery was decided on the basis of fracture. After prepping, draping the first step was longitudinal traction. Decided configuration of plates were mapped on the draped limb. Minimally invasive medical and lateral approach was used and if required as per fracture configuration posteromedial and posterolateral open approaches were used. Distal incision was used for plate adjustment usually 2 screws were inserted (Fig 3).

Articular congruity was achieved depending on the type of depression and fracture pattern. (Fig 4).

The depressed articular fragments were elevated through planned window and were temporarily fixed using multiple parallel K-wires. Varus/ Valgus alignment was corrected using subchondral $3 \mathrm{~mm} \mathrm{~K}$-wire as joystick in proximal fragment. Fixation was executed using appropriate buttress plate and/or locking anatomical raft plate. Before application of the plate the subchondral $\mathrm{K}$-wires were pulled through from the other side using "pass through" technique to ease application and positioning of the plate(3). Temporary subchondral K-wire were then replaced by long $(55 \mathrm{~mm}-80$ $\mathrm{mm}) 3.5 \mathrm{~mm}$ cortical screws as raft screws/ grid screws through the anatomical locking raft plate to hold the reduced articular fragment. The use of plates on lateral pillar incorporating the raft screws is preferred to screws outside the plate ${ }^{[12]}$. A raft plate with $3.5 \mathrm{~mm}$ screws or locking screws as per the implant was used in raft configuration ${ }^{[13]}$. The author emphasized on using a bump below the ipsilateral hip to keep the hip in internal rotation and avoid inadvertent internal rotation deformity in tibia while applying traction during fixation. In some patient's femoral distractor was used to achieve axial alignment. After fixation limb was checked for ligament instability and fixation of fragments using cortical screws was then decided. Tourniquet were deflated before closure and adequate hemostasis was achieved.

\section{Post-operative management}

Lower Limbs were elevated and no plaster splint was used. Deep breathing exercises were instituted from same day. Sitting on edge of bed and toe touch standing using a walker support was instituted from next day.

\section{Classification for depressed articular fragment, technique of elevation}

Depression was classified into five types and Type 1 was further sub-classified into 4 types.

\section{Type a central depression}

1. PIT Depression: This type of depression is usually seen in the depressed lateral tibial condylar fracture. While elevating this type of depression (Pit) it is important to determine the location of the articular fragment, as it can be located anteriorly, posteriorly or in the center. Accordingly, the site for window is chosen (Fig 5), if the pit has multiple comminuted fragments then a disc of cortical bone graft was used before placing the bone tamp beneath the depression to elevate multiple fragments as one chunk, if the depressed fragments are not aligned 
properly then sub-meniscal approach is utilized. After elevation, before removing the bone tamp subchondral hold of fragments is ensured by properly placed subchondral $\mathrm{K}$ wires.

2. Collapsing roof: The visual appearance of this type of depression on radiograph is like a collapsed roof, where the centrally depressed condylar is tilted and is still hinged to the rest of articular surface. Elevation of collapsing roof is done as one fragment elevation at the deepest part of depression and is well done by large bone tamp, successive blows on the bone tamp under image intensifier gives a classical "motion picture effect". Immediately after adequate elevation, the splaying of condyles (condylar widening) is seen which needs to be compressed with condylar clamps (Fig 4) and subchondral K-wire hold is given temporarily till the complete fixation. This is the second most common type of central depression (Fig 6).

3. Sinking Boat: This depression is almost similar to the collapsing roof appearance, the only difference is that the medial part involves the part of tibial spine and that part goes into the joint appearing as 'sinking boat', THE other end of the fragment is tilted in depth, this is the only subtle difference with the collapsing roof appearance. This depression is elevated similarly to a collapsed roof fragment but requires fixing the medial end first with $\mathrm{K}$ wire.(Fig 7)

4. Free Floating: It is a central depression in which the articular fragment is pushed way deep. This fragment is elevated and brought near the articular surface using medial or lateral window and if it is not found well aligned on image intensifier a sub meniscal arthrotomy is performed to align the fragment. If the meniscus is found to be entrapped, it is restored to its position by dura elevator, with an instrument template below the meniscus. After the elevation and temporary subchondral $\mathrm{K}$-wire fixation void is filled with bone graft or bone substitute and fixation is completed by raft screws and plate and meniscus is sutured in position with soft tissues or through suture anchors. (Fig 8)

Type B. Depressed fragment with wide splaying of metaphysis: Thrusting of femoral condyle into the tibial condyle leads to depression of condylar along with wide splaying of the metaphysis. This requires elevation of the depressed condylar thorough appropriate cortical window and splaying is reduced with condylar clamps. A modification was made in the tibial condylar clamp for this purpose, hence to increase the surface area an inbuilt anatomical template plate was incorporated on the end of the clamp. Effective compression with this clamp leads to reduction of void at the fracture site (Fig 9).

Type C. Locked displaced lateral condyle with fragment depression: As the femoral condyle thrusts into the tibial condyle due to axial loading with valgus force, the separated lateral articular surface locks with lateral surface of the femoral condyle and lifts up with recoil. It requires a dura elevator to go between the femoral and tibial surface and dislodge the fragment and push it below the femoral condyle. After reduction and getting it back into position, with joystick, tibial condylar clamp is applied for reduction of condylar width, depressed fragment is elevated, and subchondral $\mathrm{K}$ wire hold is obtained and fixation is completed after ensuring lateral meniscus is restored to its position. (Fig 10)

Type D. Depressed whole condylar fragment: It is the complete condyle separated from the metaphysis and requires use of multiple $3 \mathrm{~mm}$ subchondral joysticks in both the condylar halves and use of 2 condylar clamps. The reduction is performed under sustained traction and articular alignment is achieved using a cannulated bone tamp or drill sleeve. Once the correct articular profile is obtained under image intensifier, subchondral K-Wires are inserted to temporarily hold the reduction, later to be replaced by raft screws and final fixation. There is no need of tamp and window for elevation of this depression (Fig 11).

Type E. Complex depression: It occurs mainly in bicondylar comminuted injuries with articular depression of medial and lateral condyles in both sagittal and coronal planes. Requires the combined skills and is best managed by use of multiple joysticks, opportunity windows, sub meniscal approach, apex holding mini plates and multiplanar hold and fix strategy (Fig 12).

Statistical analysis: All data analysis was done using SPSS 11.0 (SPSS Inc., Chicago IL). Descriptive statistics were used to determine ranges, means, and standard deviations. Paired ttest was used to determine the difference between two means. Correlations were analysed by using the Pearson correlation coefficient. A $p$ value of $<0.05$ was considered statistically significant.

\section{Results}

All the cases were retrospectively evaluated by first author for various types of depressed cases of tibia condylar injury were managed at our center. Out of 1210 cases, 95 cases with Schatzker type 1 injury, 15 cases with bilateral tibial condylar injury, 62 cases with compound fractures, 18 cases with compartment syndrome and 12 cases with neuro vascular injury and 58 patients who could not come for follow up were excluded from the study. Remaining 950 cases were enrolled for our study. There were 651 males and 299 females with an average age of $46.72 \pm 10.84$, (20 -70years). 410 fractures were on the Left side and 540 cases were on right side. Thus all fractures included this study were closed fractures without any distal neurovascular injury or compartment syndrome. A total of 453 cases were classified as Schatzker type 2, 42 were classified as type 3, 45 cases were classified as type 4, 112 cases were classified as type 5 and 298 cases were classified as type 6 . In our study 38 patients had diabetes, 1 hemophilia, 74 hypertension, 1hyperuricemia and 6 hypothyroidism,7 ischaemic heart disease and 2 with psoriasis. The most common mechanism of injury in our study was road traffic accidents 724 followed by 123 patients with domestic fall.

In our study most common type seen was type A 494 cases followed by type E 180 cases, Type B with 175 cases, Type C 45 cases and Type D with 56 cases.

The average tissue response time (time from injury to optimum soft tissue condition before surgery) in our study was $7.23 \pm 1.38,(1-10$ days). Mean operative time was $92.04 \pm$ 23.14 minutes (55 to 140 minutes). Mean Post op condylar tilt $5.38^{\circ} \pm 3.55\left(0^{\circ}-12^{\circ}\right)$, mean post op condylar widening 2.68 $\mathrm{mm} \pm 1.25$, (0 to $6 \mathrm{~mm})$, mean post op articular step $2.98 \mathrm{~mm}$ $\pm 1.86,(0$ to $8 \mathrm{~mm})$ and mean post op valgus tilt $6.64^{\circ} \pm 3,\left(0^{\circ}\right.$ - 
$13^{\circ}$ ). All the cases were followed up for at least 24 months and mean follow-up time was $87.39 \pm 35.97$ months. The average radiographic bony union time was $17.07 \pm 1.4$ (14-22 weeks) and the average full weight bearing time was 15.04 $\pm 2,(12-24$ weeks). Secondary varus deformity was found in 15 cases, secondary, screw loosening postoperatively was found in 13 cases, secondary osteoarthritis was found in 36 cases and 4 patients went for total knee arthroplasty. Superficial wound discharge, with negative culture was found 7 cases, deep infection was found in 10 cases and delayed infection was found in 17 cases. Superficial wound infections healed with nonoperative wound management, deep and delayed infection required debridement and application of negative pressure wound therapy in stable fixations and removal of implant and external fixation in form of extra cutaneous plate fixation.

In this study mean knee society score at 12 months postoperatively were 84.39 (60-98). The average range of motion of the affected knees at 12 months was $127.6^{\circ}\left(120^{\circ}\right.$ $\left.135^{\circ}\right)$. Mean knee society score improved to 87.66 at 24 months with statistically significant p-value of $<0.001 \mathrm{using}$ paired t-test and improvement in knee range of motion 24 months was also statistically significant with $\mathrm{p}$ - value of $<0.001$ obtained using paired t-test. The functional outcome was excellent in 756 patients (80-100), good in 179 patients (70-79), fair 13(60-69) and poor in only 2 patients $(<60)$.

Table 1: Descriptive statistics for different parameters

\begin{tabular}{|c|c|c|c|c|c|c|}
\hline Parameters & Levels & Number & Percent & Mean & Median & $\begin{array}{l}\text { Standard } \\
\text { Deviation } \\
\end{array}$ \\
\hline \multirow{3}{*}{ Age in years } & $<=30$ & 86 & $9.1 \%$ & & & \\
\hline & $31-50$ & 528 & $55.6 \%$ & & & \\
\hline & $51-70$ & 336 & $35.4 \%$ & & & \\
\hline \multicolumn{2}{|c|}{ Age in years } & & & 46.72 & 48.00 & 10.84 \\
\hline \multirow{2}{*}{ Sex } & Female & 299 & $31.5 \%$ & & & \\
\hline & Male & 651 & $68.5 \%$ & & & \\
\hline \multirow{8}{*}{ Comorbidities } & Diabetes & 38 & $4.0 \%$ & & & \\
\hline & Haemophilia & 1 & $.1 \%$ & & & \\
\hline & Hypertension & 74 & $7.8 \%$ & & & \\
\hline & Hyperuricemia & 1 & $.1 \%$ & & & \\
\hline & Hypothyroidism & 6 & $.6 \%$ & & & \\
\hline & $I H D$ & 7 & $.7 \%$ & & & \\
\hline & Psoriasis & 2 & $.2 \%$ & & & \\
\hline & None & 821 & $86.4 \%$ & & & \\
\hline \multirow{5}{*}{$\begin{array}{c}\text { Schatzker } \\
\text { classification }\end{array}$} & Type 2 & 453 & $47.7 \%$ & & & \\
\hline & Type 3 & 42 & $4.4 \%$ & & & \\
\hline & Type 4 & 45 & $4.7 \%$ & & & \\
\hline & Type 5 & 112 & $11.8 \%$ & & & \\
\hline & Type 6 & 298 & $31.4 \%$ & & & \\
\hline \multicolumn{2}{|c|}{ Operation time [min] } & & & 92.04 & 95.00 & 23.14 \\
\hline \multirow{9}{*}{$\begin{array}{l}\text { Depression } \\
\text { type }\end{array}$} & Type A, CR & 147 & $15.5 \%$ & & & \\
\hline & Type A, Ffa & 131 & $13.8 \%$ & & & \\
\hline & Type A, Ffb & 54 & $5.7 \%$ & & & \\
\hline & Type A, PD & 150 & $15.8 \%$ & & & \\
\hline & Type $A, S B$ & 12 & $1.3 \%$ & & & \\
\hline & Type B & 175 & $18.4 \%$ & & & \\
\hline & Type C & 45 & $4.7 \%$ & & & \\
\hline & Type D & 56 & $5.9 \%$ & & & \\
\hline & Type E & 180 & $18.9 \%$ & & & \\
\hline
\end{tabular}

Table 2: Post-operative descriptive statistics for different parameters

\begin{tabular}{|c|c|c|c|}
\hline Parameter & Mean & Median & Standard Deviation \\
\hline Condylar tilting (degrees) & 5.38 & 4 & 4 \\
\hline Varus/Vulgus & 6.57 & 6 & 3 \\
\hline Articular step (mm) & 3.00 & 2 & 2 \\
\hline Condylar widening (mm) & 2.68 & 2 & 1 \\
\hline
\end{tabular}

Table 3: Comparison of knee society score at 12 and 24 months

\begin{tabular}{|c|c|c|c|}
\hline Knee Society Score at & Mean & Median & Standard Deviation \\
\hline 12 months & 84.39 & 85.00 & 6.37 \\
\hline 24 months & 87.66 & 88.00 & 6.31 \\
\hline Difference of KSS & 3.29 & 3.00 & 2.44 \\
\hline P-value* & \multicolumn{3}{|c|}{$<0.0001(\mathrm{~S})$} \\
\hline
\end{tabular}

*Obtained using paired t-test; S: Significant

Table 4: Comparison of range of movement between 12 months and 24 months

\begin{tabular}{|c|c|c|c|}
\hline Range of movement at & Mean & Median & Std. Deviation \\
\hline 12 months & 122.86 & 120 & 5.470 \\
\hline 24 months & 127.66 & 125 & 4.464 \\
\hline Difference in ROM & 4.8 & 5 & 4.578 \\
\hline P-value & \multicolumn{4}{|c|}{$<0.0001(\mathrm{~S})$} \\
\hline
\end{tabular}

*Obtained using paired t-test; S: Significant

\section{Discussion}

Tibial condylar fractures, are one of the commonest intra articular fractures which requires optimum reduction and stabilization to achieve articular congruence and axial stability. Any depression of the joint line would result in significant loss of joint function and post traumatic arthritis later ${ }^{[14,15]}$. All the classifications whether in 2D or 3D have various fixation guidelines and strategies to manage these difficult fracture patterns, however exact details for elevation technique is lacking.

There have been no such studies in previous literature and this is a first study of depressed articular fragments and an attempt to classifying depressed fracture fragments and describing modes of elevation and fixation. The execution of surgery of tibial condylar fracture is like an orchestra where fine tuning of various steps, skills and maneuvers used in sequence.

As the knowledge about the variations in fracture patterns was gained, gradual improvement in patient outcome was experienced.

In this retrospective study, all the depressions were broadly classified into 5 types and further type 1 central depression was sub classified into 4 distinct subtypes, $4^{\text {th }}$ free floating subtype was again divided into two types.

The mean age in our study was 46.72 years which corresponds to similar study by Biggi et al where mean age was forty-three years and mean age was fifty-one year in study by Meridian et al 51+16.1 years and Krause et al. ${ }^{[16-18]}$ According to meridian et al, average duration of hospital stay was 19 days while in this study average duration was 10 days with approximately 7 days being the average tissue response before surgery ${ }^{[17]}$.

Recently, advancement in surgical techniques, better implantation and anatomical reduction leads to early knee mobilization to avoid knee stiffness which reduces incidence of hospital stay.

Jain et al found that excellent anatomical restoration and rigid fracture fixation enables the facilitation of early knee motion and thus achieving optimal knee function with acceptable functional outcome (84\%), with $80 \%$ patients with excellent outcomes in our study ${ }^{[19]}$.

Mean operative time in our study was $92+23 \mathrm{mins}$, as compared to Mathew et al being $2.2 \mathrm{hrs}{ }^{[18]}$.

The average time to union in our study was 17.07 weeks compared to Average time for union was 14 weeks (range 1022 weeks), all cases fracture united within 14 weeks ${ }^{[20,21]}$.

It is a known fact that osteoporosis with increasing age is a responsible for large cases of fractures and tibial condyle fractures can result from a range of low energy to high energy 
trauma. Road traffic accident patients were the majority in this trauma series, they also include the patients from varying range of severity, some of them resulting from trivial trauma and some from high energy trauma.

To determine that the patient's limb is suitable for surgery a concept of "Tissue response time" was taken into consideration as it was authors observation that all proximal tibial fractures need not be waited for, and can be taken for surgery the same day or the next, like in cases of trivial trauma in osteoporotic patients.

With the help of the proposed classification author was easily able to plan and determine the steps. The easiest to elevate were those fragments which maintained alignment or continuation with the main intact articular condylar pit depression, roof collapse, sinking boat using bone tamp in a predetermined trajectory. The trajectory of bone tamps, the size and shape of tamp surface of the bone tamp requires selection, depending on the trajectory of deforming force and the tilt of the fragment. Koval et al described use of direct elevation of the depressed fragment through the fracture site using open book approach for schatzker type 2 fractures, they also described using a window from the opposite cortex for elevating the tilted fragment. The main objectives when treating articular fractures of the knee are the restoration of articular congruity and stability, the axial and rotational alignment of the lower limb and stability and early motion of joint ${ }^{[22]}$.

The author used bone locking and non-locking constructs for fixation. Non-locking methods for fixation were used along with the raft of cortical 3.5 screws while dealing with depressions in cases of Schatzker type 5 and 6 fractures, though in some cases of type 2 and type 4 non-locking construct was used to achieve compression at fracture site. Locking raft construct was used for holding the depressed fragment in Schatzker type 2 and type 3 cases. A combination of locking and non-locking construct was also used in some case where there was gross comminution on lateral as well as medial side.

Rate of secondary osteoarthritis at the end of two year follow up was only 4 percent in the present study, of which majority of patients were from type 5 and type 6 category of Schatzker classification system and type E complex fracture group from our classification, comparable with a study showing 5\% incidence of secondary osteoarthritis that necessitated reconstructive surgery (total knee arthroplasty, realignment osteotomy, knee arthrodesis) ${ }^{[23]}$.

A few cases of simple split depression also developed osteoarthritis in our series. In two cases we did arthroscopic examination during the course of follow-up and we found out the degeneration of the cartilage was more on the medial side.

\section{Limitation of our Study}

This is a single center, retrospective study and also MRI study could not be done in all patients. Lack of comparison group, validation of classification, use of different implants was a necessity. We were unable to have inter and intra observer reliability.
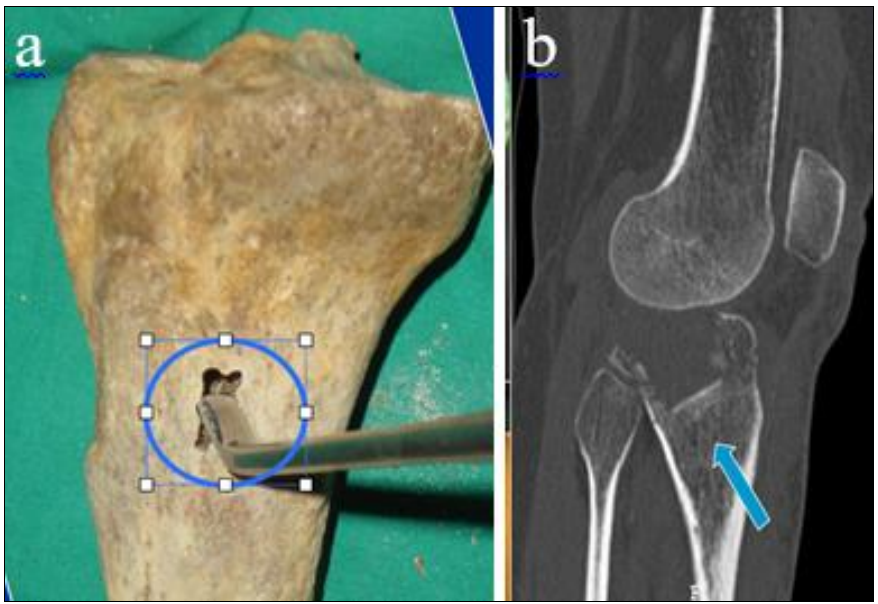

Fig 1: Planning elevation

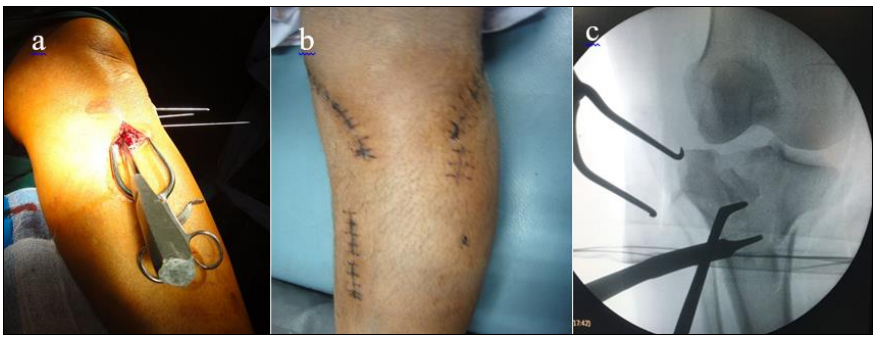

Fig 2a, b, c: Medial and Lateral window with insertion of bone tamp, and case requiring lateral window

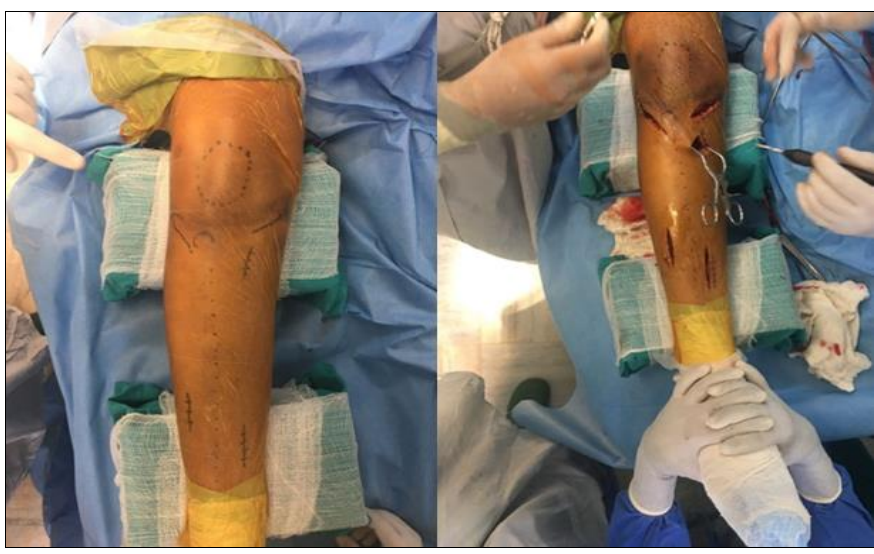

Fig 3: Planning incisions.

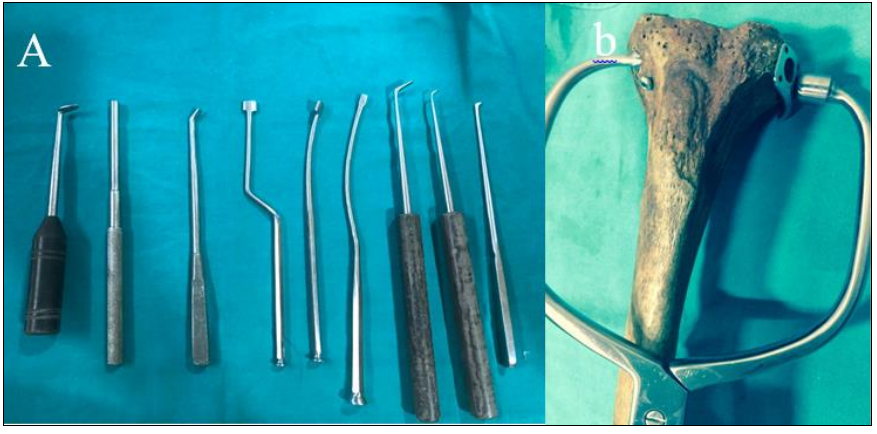

Fig 4: Punches and Chandak Plate Bone clamp 


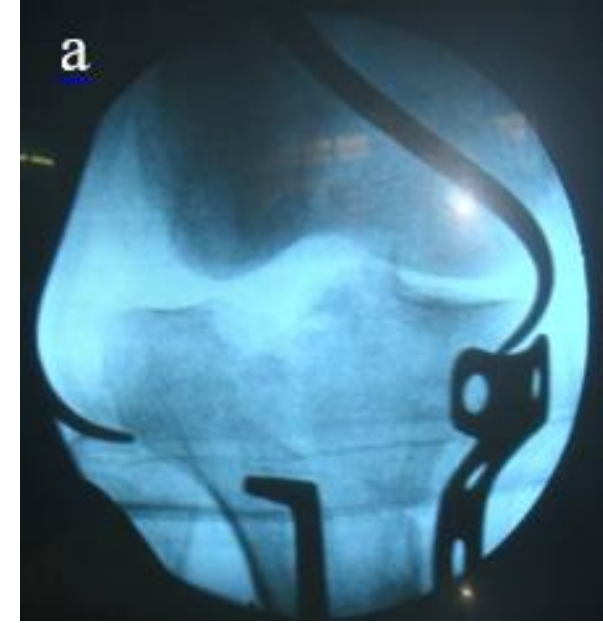

Fig 5: Pit depression

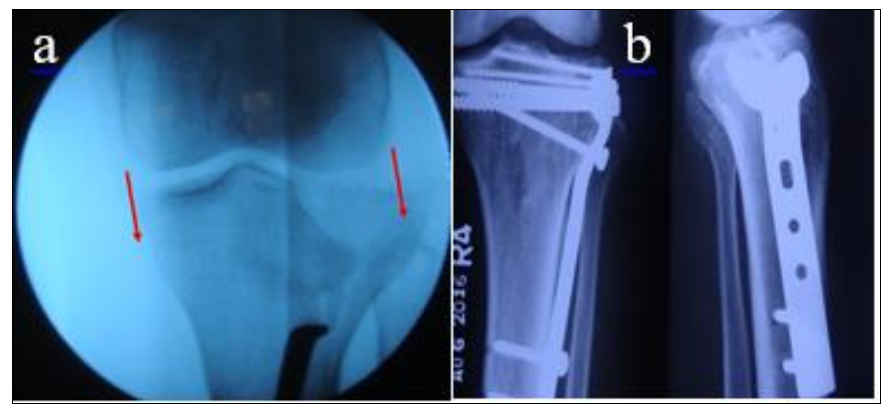

Fig 6: Collapsing roof

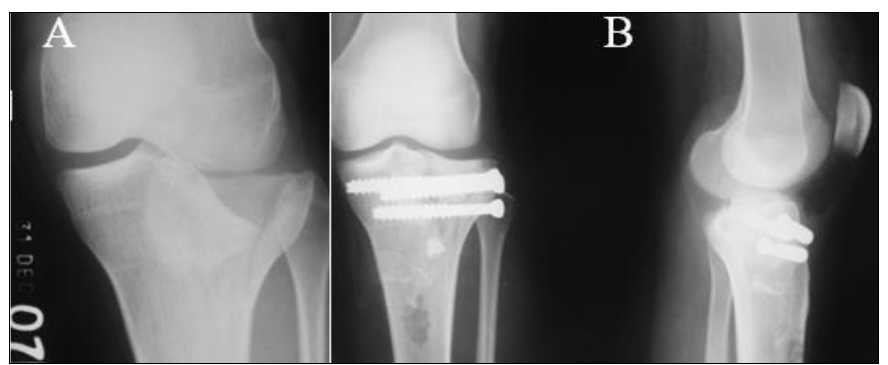

Fig 7: Sinking boat.
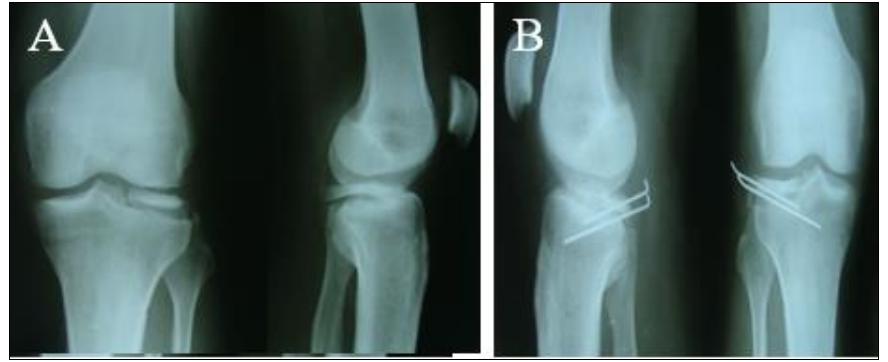

Fig 8: Free floating fragment in the joint 'topsy turvy'.

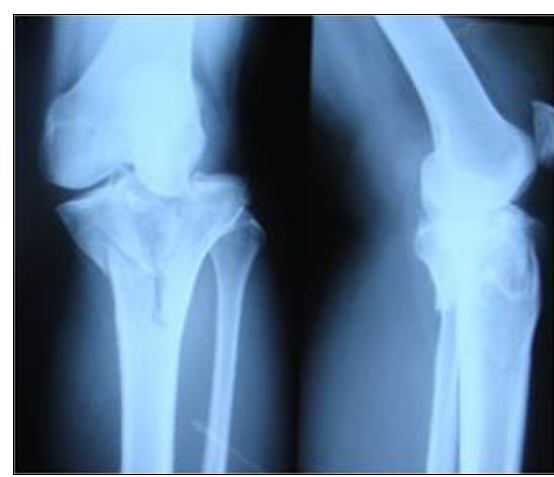

Fig 9: Depressed fragment with splaying metaphysis.

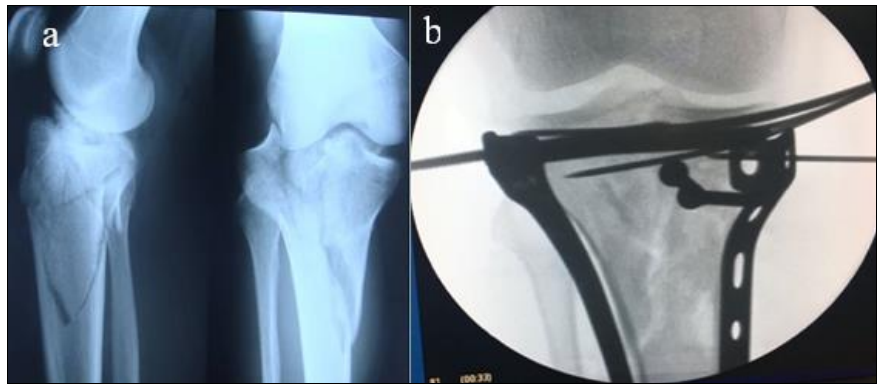

Fig 10: Locked displaced lateral condyle with fragment depression.

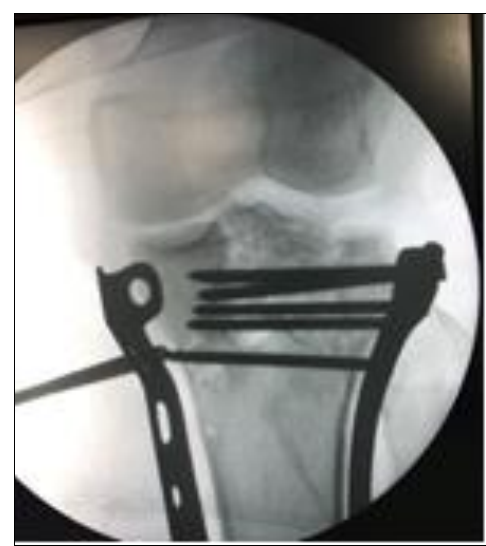

Fig 11: Depressed whole condylar fragment.

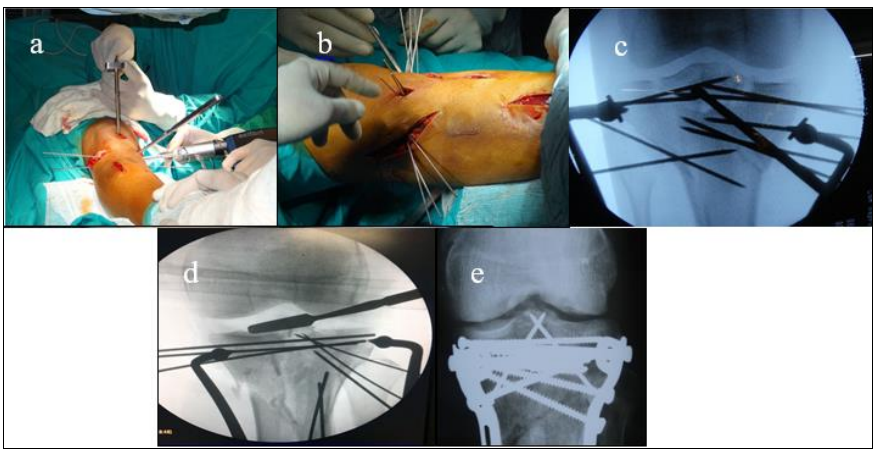

Fig 12: Complex depression.

\section{Conclusion}

Based on our classification of the various types of depression of articular surface in tibial condylar fractures, and our algorithm for elevation of depressed articular fragment to restore articular congruence and our proposed. Algorithm we were able to standardize the steps of elevation of depressed fragment and stabilize the same fragments. The main advantage of using our classification system is that it helps in recognizing the depression pattern and guides the trajectory for the bone tamp or elevator. In this retrospective study, depressed tibial condylar fractures were identified and studied. The elevations were fixed with either locking/ nonlocking plates and cannulated cancellous screws depending on the type of depression and fracture pattern.

\section{References}

1. Prat FS, Camacho CP. Treatment strategy for tibial condylar fractures: an update. EFORT Open Rev. 2016;1:225-32. Available from: www.efort.org/openreviews

2. Bai B, Kummer FJ, Sala DA, Koval KJ, Wolinsky PR. Effect of articular step-off and meniscectomy on joint alignment and contact pressures for fractures of the lateral tibial condylar. J Orthop Trauma. 2001;15:101-6. 
3. Maniar H, Kubia EN, Horwitz DS. Tibial Condylar Fractures. In: III PT, Ricci WM, Ostrum RF, Mcqueen MM, McKee MD, Court-Brown CM, eds. Rockwood and Green's fractures in adults. Ninth ed. Philadelphia: Wolters Kluwer; 2020, 4231-324.

4. Hohl M, Moore T. Articular fractures of the proximal tibia. In: Evarts C, editor. Surgery of the musculoskeletal system. 2nd ed. New York: Churchill Livingstone; 1990.

5. Schatzker J, Mcbroom R. The Tibial Condylar Fracture: The Toronto experience 1968-1975. Clin Orthop Relat Research. 1979;138:94-104.

6. Marsh JL, Slongo TF, Agel J, Broderick JS, Creevey W, DeCoster TA, et al. Fracture and dislocation classification compendium-2007: Orthopaedic Trauma Association classification, database and outcomes committee. J Orthop Trauma. 2007;21:S1-133. Available from: http://www.ncbi.nlm.nih.gov/pubmed/18277234

7. Krause M, Preiss A, Müller G, Madert J, Fehske K, Neumann MV, et al. Intra-articular tibial condylar fracture characteristics according to the "Ten segment classification." Injury. 2016;47:2551-7. Available from: http://dx.doi.org/10.1016/j.injury.2016.09.014

8. Zhu Y, Yang G, Luo CF, Smith WR, Hu CF, Gao H, et al. Computed tomography-based Three-Column Classification in tibial condylar fractures: Introduction of its utility and assessment of its reproducibility. J Trauma Acute Care Surg. 2012;73:731-7.

9. Koval KJ, Helfet DL. Tibial Condylar Fractures: Evaluation and Treatment. J Am Acad Orthop Surg 1995;3:86-94.

10. Pizanis A, Garcia P, Pohlemann T, Burkhardt M. Balloon Tibioplasty: A Useful Tool for Reduction of Tibial Condylar Depression Fractures. J Orthop Trauma. 2012;26:e88-93.

11. Buchko GM, Johnson DH. Arthroscopy assisted operative management of tibial condylar fractures. Clin Orthop Relat Res. 1996;332:29-36.

12. Kulkarni SG, Tangirala R, Malve SP, Kulkarni MG, Kulkarni VS, Kulkarni RM, et al. Use of a raft construct through a locking plate without bone grafting for splitdepression tibial condylar fractures. J Orthop Surg. 2015;23:331-5.

13. Cooper HJ, Kummer FJ, Egol KA, Koval KJ. The effect of screw type on the fixation of depressed fragments in tibial condylar fractures. Bull Hosp Jt Dis. 2001;60:72-5.

14. Manidakis N, Dosani A, Dimitriou R, Stengel D, Matthews S, Giannoudis P. Tibial condylar fractures: Functional outcome and incidence of osteoarthritis in 125 cases. Int Orthop. 2010;34:565-70.

15. Volpin G, Dowd GSE, Stein H, Bentley G. Degenerative arthritis after intra-articular fractures on the knee. Longterm results. J Bone Jt Surg - Ser B. 1990;72:634-8.

16. Biggi F, Di Fabio S, D’Antimo C, Trevisani S. Tibial condylar fractures: internal fixation with locking plates and the MIPO technique.

17. Märdian S, Landmann F, Wichlas F, Haas NP, Schaser $\mathrm{KD}$, Schwabe P. Outcome of angular stable lock- ing plate fixation of tibial condylar fractures Midterm results in 101 patients. Indian J Orthop. 2015;49:620-9.

18. Krause M. Intra-articular tibial condylar fracture characteristics according to the "Ten segment classification". Injury, 2016.

19. Jain RK, Shukla R, Baxi M, Agarwal U, Yadav S. Evaluation of functional outcome of tibial pla- teau fractures managed by different surgical modalities. Int $\mathbf{J}$
Res Orthop. 2016;2:5-12.

20. Vasanad GH, Antin SM, Akkimaradi RC, Policepatil P, Naikawadi G. Surgical management of tibial condylar fractures-A clinical study. J Clin Diagn Res. 2013;7:3128-30.

21. Bagul J, Dole P. Time for union in tibial condylar fracture. Natl J Integr Res Med 2015; 6:31-4.

22. Liu YK, Zhou ZY, Liu F. New developments in treatment of tibial condylar fractures. Chin Med J 2017;130:2635-8.

23. Mehin R, O'Brien P, Broekhuyse H, Blachut P, Guy P. Endstage arthritis following tibia condylar fractures: average 10-year follow-up. Can J Surg. 2012;55:87-94. 